\title{
Spontaneous unscarred fundal rupture after normal vaginal delivery
}

\author{
Shreya Thapa*, Anjali Rani, Uma Pandey, Nisha Rani Agrawal
}

Department of Obstetrics \& Gynaecology, Institute of Medical Sciences, Banaras Hindu University, Varanasi-221005, Uttar Pradesh, India

Received: 8 June 2014, Revised: 30 June 2014

Accepted: 1 July 2014

*Correspondence:

Dr. Shreya Thapa,

E-mail: drshreyathapa@rediffmail.com

(C) 2014 Thapa S et al. This is an open-access article distributed under the terms of the Creative Commons Attribution Non-Commercial License, which permits unrestricted non-commercial use, distribution, and reproduction in any medium, provided the original work is properly cited.

\begin{abstract}
Uterine rupture is one of the most dangerous obstetric situation carrying an increased risk of maternal and perinatal morbidity and mortality, associated with poorly managed labour. The incidence of spontaneous rupture of unscarred uterus is around 1 in 8000 to 1 in 15000 deliveries. We report this unusual case of spontaneous unscarred fundal rupture after normal vaginal delivery. This case under reference developed shock soon after delivery and was explored due to suspected intraperitoneal hemorrhage. This case is being reported to emphasis the need for proper post-delivery monitoring not only to diagnose post-partum hemorrhage but also to suspect uterine rupture as a cause of unexplained shock developing after delivery inspite of all resuscitative measures. Although unexpected in a woman with an unscarred uterus, rupture should be considered as a possible cause of unusual pain or hypotension in the mother. The most effective way to reduce the number of morbidity and mortality would be to prevent unwanted pregnancies by informed and effective use of contraception.
\end{abstract}

Keywords: Uterine rupture, Dilatation and curettage, Exploratory laparotomy, Uterine perforation

\section{INTRODUCTION}

Uterine rupture is defined as separation of entire thickness of uterine wall with extrusion of fetal parts and intra-amniotic contents into the peritoneal cavity. ${ }^{1}$ Uterine rupture is one of the most dangerous obstetric situation carrying an increased risk of maternal and perinatal morbidity and mortality, associated with poorly managed labour. The incidence of spontaneous rupture of unscarred uterus is around 1 in 8000 to 1 in 15000 deliveries. $^{2}$

The various risk factors of uterine rupture in an unscarred uterus are grand multiparity, injudious use of oxytocin, excessive fundal pressure, obstructed labour, uterine instrumentation (previous Dilatation and curettage for incomplete abortion). ${ }^{3}$ Pathological invasion of placenta (placenta increta percreta), instrumental deliveries, manual removal of placenta, uterine manipulation (external cephalic version), uterine malformations associated with pregnancy (e.g., pregnancy occurring in the rudimentary horn). The various risk factors in a scarred uterus are -previous caesarean section, Myomectomy or previous operative laparotomy. ${ }^{4,5}$ Spontaneous rupture is commonest at the anterior wall of the uterus (lower segment >upper segment) followed by the lateral wall. ${ }^{6}$ Fundal rupture is the rarest of all.

We report this unusual case of spontaneous unscarred fundal rupture after normal vaginal delivery. This case under reference developed shock soon after delivery and was explored due to suspected intraperitoneal hemorrhage. This case is being reported to emphasis the need for proper post-delivery monitoring not only to diagnose post-partum hemorrhage but also to suspect uterine rupture as a cause of unexplained shock developing after delivery inspite of all resuscitative measures. Active and early diagnosis and management can save the life of a young mother. 


\section{CASE REPORT}

26 years unbooked gravida 4 parity $1+$ abortions -2 living 1 at $35+6$ gestation age reported to labour room with complaints of per vaginum bleeding and pain abdomen. She had previous history of normal delivery 3 years back. She also gave history of spontaneous abortions at 2 months gestation which were each evacuated by dilatation and curettage on two occasions year back after which the lady had conceived spontaneously in the next cycle. On examination patient was in early labour and fetal heart was absent by stethoscope and confirmed by ultrasound. She eventually delivered a fresh intra uterine dead baby female of $2.2 \mathrm{~kg}$. There was no history of oxytocin usage or fundal pressure application during the delivery.

The patient was observed in labour room but before shifting the patient to the ward, she became dyspneic, Respiratory rate $-40 / \mathrm{min}$ and blood pressure of $80 / 40$ with tachycardia of 140/minutes. Patient had mild abdominal distension. Uterus was 16 weeks well contracted and there was no active vaginal bleeding. She was immediately started on fluids and inotropes. Hemoglobin and coagulation profile sent. Hemoglobin was $7 \mathrm{gm} / \mathrm{dl}$ and INR-1. Two pints packed cells and 4 FFP were immediately transfused. Urgent ultrasound scan revealed post-partum bulky uterus with haemoperitoneum with small bowel obstruction.

Patient was taken for immediate exploratory laparotomy under high risk consent.

About 2 liters of blood was present in the peritoneal cavity and $2 \times 1.5 \mathrm{~cm}$ rent present in fundus.

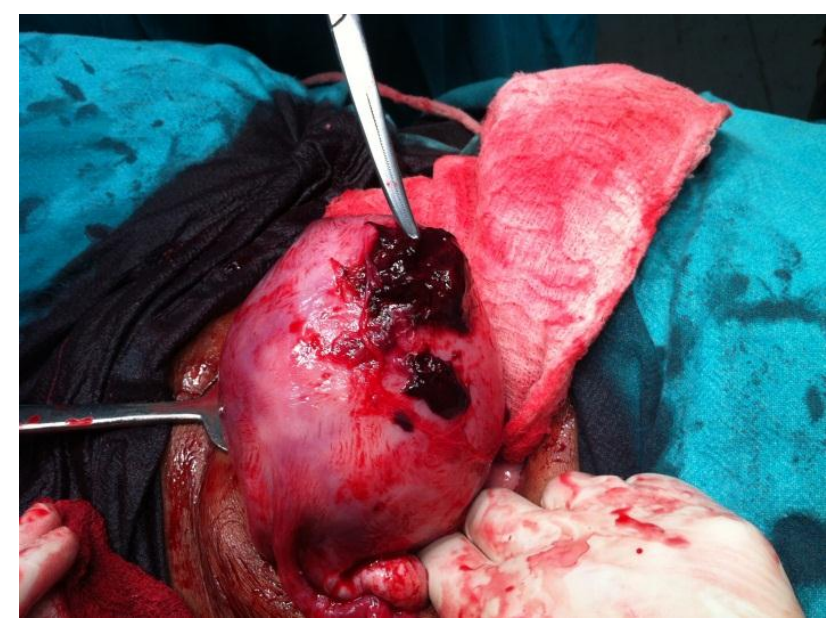

Figure 1: A $2 \times 1.5 \mathrm{~cm}$ rent present in fundus of the uterus.

Closure of uterine perforation was done. Bowel loops were distended but there was no evidence of bowel perforation. In this case the cause of uterine rupture could be attributed to the two dilatation and curettage that the patient underwent before she conceived this baby.
The post-operative period was uneventful and patient improved dramatically. She was discharged on postoperative day 10 on advice about diet and family planning.

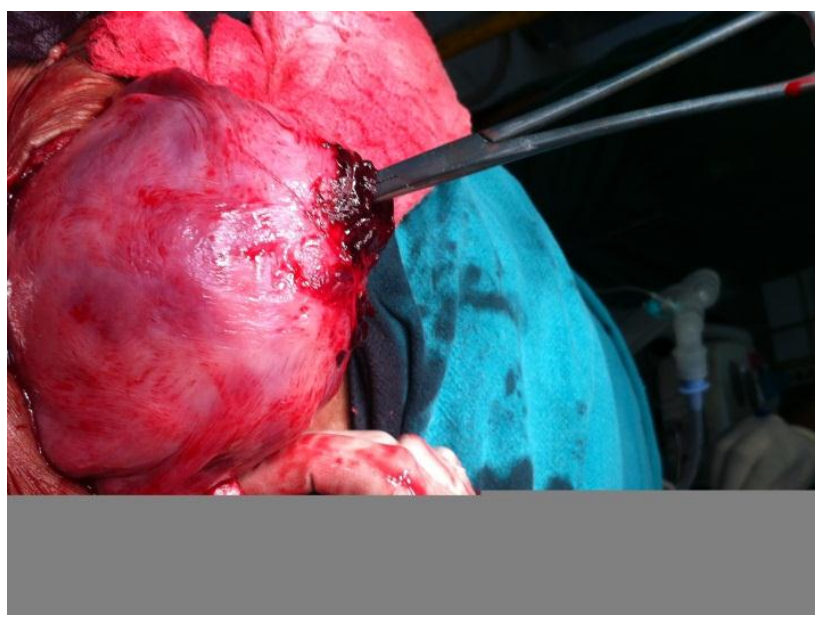

Figure 2: A $2 \times 1.5 \mathrm{~cm}$ rent present in fundus of the uterus.

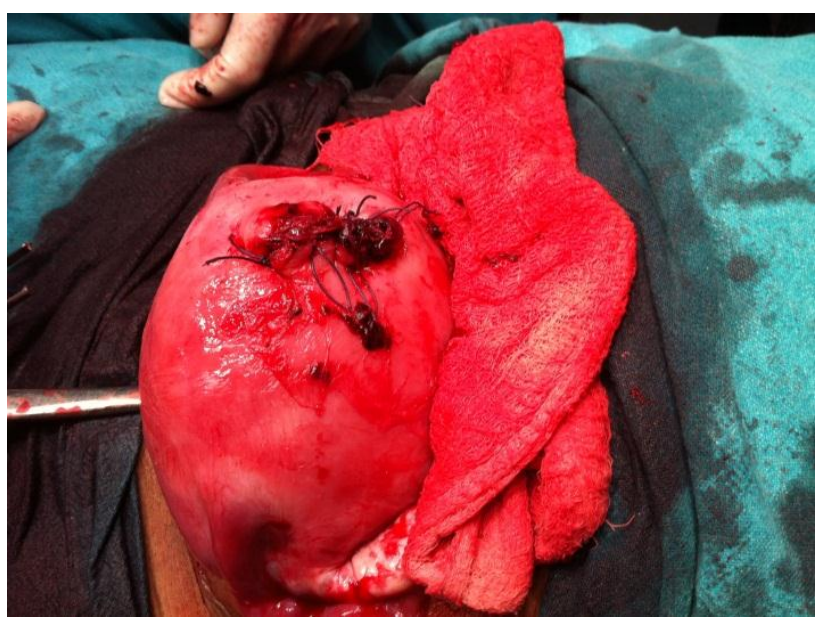

Figure 3: The rent is closed with No. 1 vicryl in two layers.

\section{DISCUSSION}

Rupture of the pregnant uterus, similar to the rupture of any internal organ, can be life threatening to the mother and the fetus. Previous uterine surgery is the most common risk factor. In a nationwide study done in Netherlands the incidence of rupture in unscarred and scarred uterus is approximately 0.7 and 5.1 per 10000 deliveries respectively. ${ }^{7}$

It is likely that in our case rupture of uterus was precipitated by unscrupulous dilatation and curettage done a year back. Complications of unsafe abortion account for an estimated $13 \%$ of maternal deaths world over or 70000 deaths per year .Lack of education, social stigma and other barriers to abortion, force women to seek abortion in secrecy at a high cost, leaving the 
poorest, least educated women to unskilled and highly unscrupulous executors and hence the greatest risk of injury.

Abortion when legal should be safe.

\section{CONCLUSION}

Although unexpected in a woman with an unscarred uterus, rupture should be considered as a possible cause of unusual pain or hypotension in the mother. The most effective way to reduce the number of morbidity and mortality would be to prevent unwanted pregnancies by informed and effective use of contraception.

Funding: No funding sources

Conflict of interest: None declared

Ethical approval: Not required

\section{REFERENCES}

1. Ofir K, Sheiner E, Levy A, Katz M, Mazor M, Uterine rupture: difference between scarred and unscarred uterus. Am J Obstet Gynaecol. 2004;191:425-9.
2. Pan HS, Huang LW, Hwang JL, Tsai YL, Cheng WC. Uterine rupture in an unscarred uterus after application of fundal pressure. A case report. J Reprod Med. 2002;47(12):1044-6.

3. Ayoubi JM, Fanchin R, Lesourd F. Rupture of a uterine horn after laparoscopic salpingectomy: a case report. J Reprod Med. 2003;48(4):290-2.

4. Dubuisson JB, Fauconnier A, Deffarges JV. Pregnancy outcome and deliveries following laparoscopic myomectomy. Hum Reprod. 2000;15(4):869-73.

5. Matsue K, Shimoya K, Shinakai T. Uterine rupture of cesarean scar related to spontaneous abortion in first trimester. J Obstet Gynaecol Res. 2004;30(1):34-6.

6. Saha SK, Dey KC. A case of spontaneous rupture of posterior wall of pregnant uterus. J Obstet Gynaecol India. 2000;50:116.

7. Zwart JJ, Richters JM, Ory F, de Vries JI, Bloemenkamp KW, van Roosmalen J. Uterine rupture in the Netherlands: a nationwide populationbased cohort study. BJOG. 2009;116(8):1069.

DOI: $10.5455 / 2320-1770 . i j r c o g 20140920$

Cite this article as: Thapa S, Rani A, Pandey U, Agrawal NR. Spontaneous unscarred fundal rupture after normal vaginal delivery. Int J Reprod Contracept Obstet Gynecol 2014;3:780-2. 